\title{
Mother-Infant Attachment at the Age of 1 Year in Recipients of Developmental Care After Preterm Birth
}

\author{
Shirin Hasanpour ${ }^{1}$, Elaheh Ouladsahebmadarek ${ }^{1^{*}}$, Mohammad Bagher Hosseini ${ }^{2}$, Mojgan Mirghafourvand ${ }^{3}$, \\ Seifollah Heidarabadi ${ }^{4}$, Mohamad Asghari Jafarabadi ${ }^{5}$
}

\begin{abstract}
Objectives: Premature birth and subsequent admission to the neonatal intensive care unit impair the mother-infant attachment process. The present study aimed to determine the impact of developmental care on the mother-child attachment at the adjusted age of 1 year.

Materials and Methods: In a quasi-experimental study, 105 premature infants born in Al-Zahra hospital of Tabriz at a gestational age of 26 to 32 weeks and a weight of $1500 \mathrm{~g}$ or less were assigned to three groups of 35 . The control group, intervention group 1 , and 2 received routine care, developmental care in the neonatal intensive care unit (NICU) and neonatal unit, developmental care in the delivery room or operation room, respectively. The mother-child attachment at the adjusted age of 1 year was measured using Maternal Postnatal Attachment Scale.

Results: The mean (standard deviation) score of the mother-child attachment at the adjusted age of 1 year in the control group, intervention group 1 and 2 was determined to be 83.8 (6.9), 81.7 (5.7), and 81.4 (6.7), respectively. The results indicated no significant difference between the three groups in terms of the score of mother-child attachment and its subscales.

Conclusion: In this study, high score of the mother-child attachment was observed in all three groups. Given the importance of developmental care and support to mothers of premature infants as well as the newness of developmental care in Iran, it seems necessary for authorities to pay more attention to this type of care and conduct further research on this subject.

Keywords: Attachment, Developmental care, Premature infant
\end{abstract}

\section{Introduction}

About 13 million preterm labors annually occur in the world, with a reported prevalence of $5 \%$ to $12 \%$ in developed countries and up to $40 \%$ in developing countries (1). According to recent studies, the prevalence of preterm labor in Iran is $7 \%$ to $8 \%$ (2). Although technological advances in the care of infants have increased the survival of premature infants, they have failed to reduce the risk of developmental delay, physical disabilities, and behavioral disorders in this group of infants (3).

The quality of the primary mother-child interaction is one of the factors that influence the adverse effects of preterm labor and positively affect the abilities and further development of children (4-8). Attachment is defined as a strong emotional relationship between the child and his/her mother or babysitter (9) which is essential for the health and development of infants (10). The most important time for the mother-infant attachment process has been mentioned to be the first 45 to 60 minutes after birth (11) which begins with behaviors such as touching, kissing, hugging, talking, smelling and making eye contact with the infant by the mother (12).
Premature birth and subsequent admission to the neonatal intensive care unit (NICU) cause disengagement or delay in the mother-infant attachment process (13). Usually, the mother of a premature infant is not ready to be separated from the fetus. This early separation causes fear for infant's safety and health and increases the risk of psychological problems such as anxiety and depression in mothers which can negatively affect the mother-infant interaction (14-18). On the other hand, the feeble nature of premature infants makes them passive in situations of mother-child interaction and disrupts the mother-child bonding process (19). Studies have shown that there is a disruption to the attachment process in premature infants hospitalized in NICU compared to other infants $(16,20)$.

Family-centered developmental-supportive interventions, which relieve infant stress and pain, support infant self-regulation, and encourage further presence of parents at infants' bedside, cause an increase in bonding and attachment and positively affect different aspects of brain development $(21,22)$.

During the hospitalization of infants in NICU, familycentered interventions reduce maternal stress and 
depression, increase maternal self-confidence and leave positive impacts on the mother-infant interaction (2325). In this regard, mothers of premature infants have expressed their need for support to play their parenting role and acquire information about infant development aid (26).

Developmental care is a family-centered care in which nursing and medical interventions are used to reduce stress in premature infants (27). The project of developmental care has been started since 2013 as a pilot project in 4 hospitals in Iran, including Al-Zahra hospital of Tabriz. These interventions have been designed for the favorable neuro-behavioral development of infants and involve reducing the environmental stressors known to cause physiological and behavioral disorders such as light and sound, organizing care interventions, parent participation, and kangaroo mother care (28).

A study by Kleberg et al showed that implementation of developmental care in the form of NIDCAP (Neonatal Individualized Developmental Care and Management Program) for premature infants in the NICU have a positive effect on the mother-child interaction (29), while a study conducted by Meijssen et al about attachment of the mother of premature infants and the effect of early intervention based on NIDCAP showed no significant difference between the intervention and control groups in terms of maternal attachment (30). Some studies indicate that the mother-infant attachment can be increased by implementing empowerment programs for mothers of infants hospitalized in NICU, as part of developmental care $(31,32)$. On the other hand, the study of Melnyk et al suggested no significant impact in this regard (33). A systematic review of studies in this field indicates reduced maternal depression and anxiety following the implementation of mother empowerment program in NICU which can have a positive impact on the quality of mother-child interaction (34). Given the conflicting results of studies and the limited number of studies on developmental care and its long-term outcomes, the present study aims to determine the impact of developmental care on the mother-child attachment at the adjusted age of 1 year.

\section{Materials and Methods}

Study Design and Participants

The present research was a double-blind quasiexperimental study (evaluators of outcomes and analyzers of data were blind to experimental groups), which was conducted in Al-Zahra hospital of Tabriz in the period from 2013 to 2017.

The inclusion criteria were parents willingness to participate in the study, gestational age of 26 to 32 weeks at birth, birthweight of less than or equal to $1500 \mathrm{~g}$, birth in Al-Zahra hospital of Tabriz, non-use of alcohol or drugs during pregnancy by mother, and receiving mechanical ventilation or continious positive airway pressure (CPAP) in the first 3 hours of birth and its continuation for at least 24 hours. In addition, the exclusion criteria were chromosomal abnormalities and congenital anomalies, severe congenital infections (e.g. HIV and TORCH), infants requiring a surgery, giving up the study by parents, and improper weight for gestational age (SGA and LGA).

Since the present paper was part of a larger research project with variables related to aspects of infant development, the sample size was determined based on a study conducted by Vamegi et al (35), considering the results related to all subscales of ASQ (Ages and Stages Questionnaire) and estimating a 20\% increase in the mean scores of infant development, at a confidence level and statistical power of $90 \%(\mathrm{M} 1=51, \mathrm{M} 2=61.2, \mathrm{sd} 1=\mathrm{sd} 2$ $=12.8, \mathrm{~b}=0.20$ and $\mathrm{a}=0.05)$. Considering a possibility of $10 \%$ reduction in the sample, the sample size was determined to be 105 to form 3 groups of 35 .

\section{Sampling and Intervention}

Sampling was done in 3 groups using convenience method and participants of all three groups were matched together in terms of gestational age and birthweight. The first group was set as the control whose participants were selected from the medical records of infants admitted to the neonatal intensive care unit of Al-Zahra hospital of Tabriz before December 2013 (before then, no developmental care was provided in the NICU and the neonatal ward). The second group (intervention 1) included infants who had received developmental care in the NICU and the neonatal ward and met the inclusion criteria. This care involved light reduction, noise reduction, pain relief, preparation of the infant's nest and positioning, training parents for participating in infant care, massage, and Kangaroo mother care (KMC). The third group (intervention 2) consisted of infants who met the inclusion criteria and had received developmental care in the delivery room or operating room and then in the NICU and the neonatal ward. Developmental care in the delivery room or operating room included cord milking, covering the infant's eyes with a hat to reduce light, dedicating a place of low noise to preterm labors, positioning, and using coated incubators for transferring these infants. Mother training programs in this group were started immediately after transferring to the postpartum ward. Developmental care during the infant hospitalization was conducted by trained personnel. In addition, necessary training for the empowerment of mothers and encouraging them to participate in their infant care in the hospital or at home was presented by the research team. Parents were also provided with the contact information of authors for emergencies.

\section{Data Collection}

After obtaining a written consent from mothers in all three groups, demographic-midwifery and infant medical background variable questionnaires were filled out by 
the author. The severity of neonatal illness was measured using CRIB (Clinical Risk Index for Babies score), which assesses the early neonatal risk, by scoring the variables of birth weight, gestational age, the maximum and minimum inspired oxygen concentration, the maximum base excess in the first 12 hours, and congenital anomalies (Table 1) (36).

The status of the mother-infant attachment at the adjusted age of 12 months was determined by MPAS (Maternal Postnatal Attachment Scale). This scale, developed by Condon and Corkindale in New York City (37). It is suitable for ages 0 to 36 months, consists of 19 items in three subscales of quality of attachment, absence of hostility, and pleasure in interaction. This scale is filled out by the mother of an infant or anyone who spends the most time with the infant. High scores indicate high mother-infant attachment and total scores of all subscale, in a range of 19 to 95 , represent the total attachment score (37). The reliability of this tool in this study was confirmed using Cronbach a (0.73).

\section{Data Analysis}

The obtained data were statistically analyzed using IBM SPSS software package (SPSS version 21.0; SPSS Inc., Chicago, IL). Descriptive statistics (frequency, percentage, mean, standard deviation and median) and inferential statistics (chi-square, Fisher exact test, one-way ANOVA and Kruskal-Wallis) were used at a significance level of $P<0.05$.

\section{Results}

The present study lasted from September 2013 until February 2017. In total, 3 participants in the control group (due to unwillingness to continue the study), 2 participants in the intervention group 1 (one due to unwillingness to continue the study and the other due to the infant's foot fracture), and 4 participants in the intervention group 2 (one due to the death of the infant in the neonatal period, one due to wrong contact information, and two because of long distance) were excluded from the study.

The mean (standard deviation) age of mothers in the control group, intervention group 1, and intervention group 2 was 28.3 (5.2), 28.5 (5.2) and 28.8 (6.1), respectively. In all three groups, the highest frequency of parents' educational attainment was average (guidance or high school). Most families had a moderate income and lived in the city. Comparison of demographic characteristics showed no significant difference among the three groups (Table 2).

The majorities of mothers in all three groups were primiparous with no history of abortion and had given birth by cesarean section. Specifications of infants' birth and mothers' obstetric history were the same in the three study groups (Table 3 ).

The mean (standard deviation) score of the motherchild attachment at the adjusted age of 1 year in the
Table 1. Clinical Risk Index for Babies score

\begin{tabular}{ll}
\hline Factor & Score \\
\hline Birth weight $(\mathrm{g})$ & \\
$>1350$ & 0 \\
$851-1350$ & 1 \\
$701-850$ & 4 \\
$\leq 700$ & 7 \\
Gestational age at birth (wk) & \\
$>24$ & 0 \\
$\leq 24$ & 1 \\
Congenital malformations & \\
None & 0 \\
Not acutely life-threatening & 1 \\
Acutely life-threatening & 3 \\
Maximum base excess in first $12 \mathrm{~h}$ (mmol/L) & \\
$>-7.0$ & 0 \\
-7.0 to -9.9 & 1 \\
-10.0 to -14.9 & 2 \\
\hline
\end{tabular}

control group, intervention group 1, and intervention group 2 was determined to be 83.8 (6.9), 81.7 (5.7) and 81.4 (6.7), respectively. The results indicated that there is no significant difference between the three study groups in terms of the score of mother-child attachment and its subscales $(P>0.05$; Table 4$)$.

\section{Discussion}

The present study aimed to determine the impact of developmental care on the mother-child attachment at the adjusted age of 1 year in premature infants born in Al-Zahra hospital of Tabriz. The mean total score of attachment (out of 95) in the control, intervention 1, and intervention 2 groups was obtained 83.87, 81.75 and 81.49, respectively. This score in all three groups was close to the maximum which shows the high level of mother-infant attachment in all groups, and no significant difference was found between them.

Kleberg et al studied the impact of NIDCAP on developmental outcomes, child behavior, and the motherchild attachment at the adjusted age of 3 years. In their study, 42 premature infants with a weight of less than $1500 \mathrm{~g}$ with no abnormality were assigned to 2 groups of 21 and NIDCAP care was started for the intervention group within 3 days after birth. The results showed that mothers in the intervention group (NIDCAP) had more eye and physical contact with their children. In addition, children in this group were mostly extrovert, expressing their feelings more easily and presenting fewer behavioral problems (29).

Feldman et al studied the impact of KMC on parental consequences at the adjusted age of 37 weeks and 3 months. For this purpose, 146 infants (73 infants in each group) with a weight of 530 to $1720 \mathrm{~g}$ and gestational age of 25 to 34 weeks were selected as the sample. Their results indicated the significant and positive impact of KMC on mother-child interactions. They concluded that 
Table 2. Parental Sociodemographic Characteristics in the Study Groups

\begin{tabular}{|c|c|c|c|c|}
\hline Variables & Control, $\mathrm{n}=35$ & Intervention 1, $\mathrm{n}=35$ & Intervention 2, n = 35 & $\boldsymbol{P}^{\mathrm{e}}$ \\
\hline Maternal age, mean (SD), year & $28.3(5.2)$ & $28.5(5.2)$ & $28.8(6.1)$ & $0.927^{d}$ \\
\hline Mothers' education levela ${ }^{a}$ No. (\%) & & & & $0.340^{b}$ \\
\hline Low & $9(25.7)$ & $7(20.0)$ & $6(17.1)$ & \\
\hline Intermediate & $18(51.4)$ & $22(62.9)$ & $16(45.7)$ & \\
\hline High & $8(22.9)$ & $6(17.1)$ & $13(37.2)$ & \\
\hline Fathers' education level ${ }^{\mathrm{a}}$, No. (\%) & & & & $0.140^{b}$ \\
\hline Low & $8(22.9)$ & $8(22.9)$ & $6(17.1)$ & \\
\hline Intermediate & $16(45.7)$ & $23(65.7)$ & $16(45.7)$ & \\
\hline High & $11(31.4)$ & $4(11.4)$ & $13(37.2)$ & \\
\hline Mothers' job, No. (\%) & & & & $0.726^{c}$ \\
\hline Housewife & $33(94.3)$ & $33(94.3)$ & $31(88.6)$ & \\
\hline Employed & $2(5.7)$ & $2(5.7)$ & $4(11.4)$ & \\
\hline Fathers' job, No. (\%) & & & & $0.518^{c}$ \\
\hline Worker & $5(14.3)$ & $2(5.7)$ & $2(5.7)$ & \\
\hline Employee & $7(20.0)$ & $9(25.7)$ & $12(34.3)$ & \\
\hline Self-employment & $23(65.7)$ & $24(68.6)$ & $21(60.0)$ & \\
\hline Family income, No. (\%) & & & & $0.118^{c}$ \\
\hline Adequate & $10(28.6)$ & $9(25.7)$ & $14(40.0)$ & \\
\hline Relatively adequate & $25(71.4)$ & $20(57.1)$ & $20(57.1)$ & \\
\hline Inadequate & $0(0.0)$ & $6(17.1)$ & $1(2.9)$ & \\
\hline Residing Place, No. (\%) & & & & $0.953^{b}$ \\
\hline Urban & $25(71.4)$ & $26(74.3)$ & $25(71.4)$ & \\
\hline Rural & $10(28.6)$ & $9(25.7)$ & $10(28.6)$ & \\
\hline
\end{tabular}

a Low, uneducated and elementary; Intermediate, guidance and high school; High, university; ${ }^{\mathrm{b}}$ Chi-square test; ${ }^{\mathrm{c}}$ Fisher's exact test; ${ }^{\mathrm{d}}$ one-way ANOVA;

e P-value 0.05 was considered significant.

Table 3. Medical Information of Mothers and Infants

\begin{tabular}{|c|c|c|c|c|}
\hline Variables & Control, $n=35$ & Intervention 1, $\mathrm{n}=35$ & Intervention 2, n = 35 & P Value ${ }^{\mathrm{e}}$ \\
\hline Gravida & & & & $0.766^{\mathrm{a}}$ \\
\hline 1 & $19(54.3)$ & $17(48.6)$ & $16(45.7)$ & \\
\hline$\geq 2$ & $16(45.7)$ & $18(51.4)$ & $19(54.3)$ & \\
\hline Parity & & & & $0.517^{a}$ \\
\hline 1 & $25(71.4)$ & $21(60.0)$ & $21(60.0)$ & \\
\hline$\geq 2$ & $10(28.6)$ & $14(40.0)$ & $14(40.0)$ & \\
\hline Abortion & & & & $0.657^{a}$ \\
\hline 0 & $27(77.1)$ & $24(68.6)$ & $24(68.6)$ & \\
\hline$\geq 1$ & $8(22.9)$ & $11(31.4)$ & $11(31.4)$ & \\
\hline Mode of delivery & & & & $0.474^{\mathrm{a}}$ \\
\hline Vaginal & $8(22.9)$ & $5(14.3)$ & $9(25.7)$ & \\
\hline Caesarean section & $27(77.1)$ & $30(85.7)$ & $26(74.3)$ & \\
\hline Gestational age, Mean in weeks (SD) & $28.5(5.2)$ & $28.4(1.4)$ & $28.3(1.3)$ & $0.874^{b}$ \\
\hline Birth weight, Mean in g (SD) & $1106.0(215.8)$ & $1095.2(211.5)$ & 1144 (234.9) & $0.627^{b}$ \\
\hline \multicolumn{5}{|l|}{ Gender, No. (\%) } \\
\hline Male & $19(54.3)$ & $14(40.0)$ & $21(60.0)$ & $0.226^{\mathrm{a}}$ \\
\hline Female & $16(45.7)$ & $21(60.0)$ & $14(40.0)$ & \\
\hline Twin, No. (\%) & $7(20.0)$ & $16(45.7)$ & $13(37.1)$ & $0.065^{c}$ \\
\hline CRIB Score, Med $\left(p_{25}-p_{75}\right)$ & $3(2-4)$ & $3(1-3)$ & $2(1-3)$ & $0.116^{d}$ \\
\hline
\end{tabular}

${ }^{\text {a }}$ Chi-square test; ${ }^{b}$ One-way ANOVA; ${ }^{\mathrm{c}}$ Fisher exact test; ${ }^{\mathrm{d}}$ Kruskal-Wallis test; ${ }^{\mathrm{e}} P$ value $<0.05$ was considered significant.

the mother's active care of the baby and physical bonding may reduce depression in mothers and increase their familiarity with interactive signals of infants (38).

The findings of both of the above-mentioned studies are not in line with the results of the present study. In these two studies, an observational instrument was used for the measurement of mother-child interaction, while a self-reporting questionnaire was used in the present study which was filled out by the mother or the first caregiver of infants.

Sohrabi studied the effect of infant massage (one of the developmental care) on attachment behaviors of mothers of infant hospitalized in the NICU. In this randomized controlled trial study, 42 mother-infant couples were selected for the control and intervention groups. Infants weighed $2500 \mathrm{~g}$ or more. Five days after the intervention, 
Table 4. Mother-Infant Attachment at the Age of 1 Year in Studied Neonates

\begin{tabular}{|c|c|c|c|c|}
\hline $\begin{array}{l}\text { Mother-Infant Attachment } \\
\text { And Subscales }\end{array}$ & $\begin{array}{c}\text { Control } \\
\mathrm{n}=32\end{array}$ & $\begin{array}{c}\text { Intervention } 1 \\
\mathrm{n}=33\end{array}$ & $\begin{array}{c}\text { Intervention } 2 \\
\mathrm{n}=31\end{array}$ & $\boldsymbol{P}^{\mathrm{c}}$ \\
\hline Attachment & $83.8(6.9)$ & $81.7(5.7)$ & $81.4(6.7)$ & $0.282^{\mathrm{a}}$ \\
\hline Quality of Attachment & $40.1(4.5)$ & $39.3(3.4)$ & $39.0(3.0)$ & $0.477^{a}$ \\
\hline Absence of Hostility & $20.0(2.9)$ & $19.0(3.5)$ & 19.5 (3.9) & $0.508^{a}$ \\
\hline Pleasure in Interaction & $23.6(2.5)$ & $23.3(1.6)$ & $22.8(2.7)$ & $0.289^{b}$ \\
\hline
\end{tabular}

a One-way ANOVA, ${ }^{\mathrm{b}}$ Kruskal-Wallis test. ${ }^{\mathrm{c}} P$-value $<0.05$ was considered significant.

maternal attachment behavior was measured by Attachment Behaviors Scale. There was a significant difference between the control and intervention groups in terms of the mean score of maternal attachment (39). This is inconsistent with the findings of the present study because, in the study of Sohrabi, the studied infants were not premature, the research tool was observational, and attachment behaviors were measured at a time different from ours.

Studies conducted by Borimnejad et al and Karbandi et al about the impact of empowerment program on the attachment of mothers with a premature infant hospitalized in the NICU indicated an increase in the mother-infant attachment following the implementation of the empowerment program. As part of developmental care, empowerment program is a multi-stage behavioral training program for premature infants and includes the ways of caring them. In both studies, the mother-infant attachment was measured before discharge from the hospital using Avant's questionnaire of mother-infant attachment behaviors $(31,32)$.

A study conducted by Meijssen et al about the attachment of the mother of premature infants and the effect of an early intervention based on NIDCAP showed no significant difference between the experimental and control groups in terms of maternal attachment. This is consistent with the findings of the present study. The supportive NIDCAP-based intervention used in their study aimed to help parents to understand the behavior of infants and their self-regulation. The participants included mothers of infants aged less than 32 weeks with a weight of below $1500 \mathrm{~g}$. The maternal attachment was measured at the adjusted age of 18 months using Working Model of the Child Interview (WMCI) in which a mother's feelings about her infant are questioned in a non-observational manner (30).

The lack of significant difference between the intervention groups after one year can be justified considering the fact that attachment between mother and child is achieved over time, and if this assessment was done in the first weeks after the intervention, there would have been a significant difference between the groups. In a study conducted by Glasser, attachment scores one week after birth in the caesarean section group was significantly lower than the natural childbirth group, while there was not such a difference between them at the age of 6 weeks (40).
In various studies, maternal age, the number of pregnancies, the number of children, infant gender, educational attainment, type of labor, place of residence, and income have been mentioned to be effective in the mother-infant attachment (40-43). In the present study, no significant difference was found between the three groups in terms of these variables. The culture prevailing in Iranian families and the value and importance given to the family and children can be mentioned among other reasons for the high level of the mother-infant attachment in the present study.

One of the main goals of developmental care is to help parents to be more sensitive and responsive to their infant signals and thereby promote the parent-child interaction (29). In this regard, it is necessary to mention the role of oxytocin in the process of attachment. This hormone increases in childbirth, breastfeeding, touching, and fondling (44), contributes to the beginning of maternal attachment behaviors, and positively affects the mental state of mothers (45). Increased maternal attachment behaviors (such as touching and having eye contact with the infant) and reduced depression affect the mental process of maternal attachment, and such mothers are more sensitive, warmer, and more adaptive. Therefore, early developmental care is of great importance in the formation of a more qualitative attachment process. Beginning of developmental care from the moment of birth in the delivery room and operating room was one of the strengths of the present study. The long-term assessment of the effects of developmental care on the mother-child attachment was another strength of this study because most studies conducted in Iran have only evaluated the short-term outcomes in this regard.

The use of a self-reporting questionnaire and trusting in the answers provided by mothers were regarded as limitations of the present study. Perhaps, an observational instrument would produce more accurate results. Developmental care in the NICU was performed by trained nurses and there was a possibility of incomplete implementation of them in some working shifts. Small sample size and impossibility of random allocation of samples was another limitation of this study. Hence, it is recommended that future studies be carried out using a larger sample size and observational instruments based on randomized controlled trial (RCT) method. Although fathers play a major role in psychological support for mothers and facilitation of the attachment process, they 
were not included in the present study. Hence, another recommendation for future research is to include fathers in developmental care programs. In addition, the attachment can be measured at different times after birth in future studies.

\section{Conclusion}

In this study, the high score of the mother-child attachment at the adjusted age of 1 year was observed in all three groups, and developmental care showed no significant impact on this score. Given the importance of developmental care and support for mothers of premature infants as well as the newness of developmental care in Iran, it seems necessary for authorities to pay more attention to this type of care and conduct further research on this subject.

\section{Conflict of Interests}

Authors declare that they have no conflict of interests.

\section{Ethical Issues}

The study was approved by the research council of Women's Reproductive Health Research Center affiliated with Tabriz University of Medical Sciences and the Ethics Committee of this university (code: 9345) and registered at the Iranian Registry of Clinical Trials website (Identifier: IRCT201405175563N5, http://irct.ir).

\section{Financial Support}

This research was financially supported by Research Deputy of Tabriz University of Medical Sciences.

\section{Acknowledgements}

The present paper was extracted from a Ph.D. thesis in Women's Reproductive Health Research Center affiliated with Tabriz University of Medical Sciences. The authors would like to thank all the staff of delivery room, operation room, neonatal ward and the NICU of Al-Zahra Hospital of Tabriz and all parents of infants who helped in conducting this research.

\section{References}

1. Villar J, Merialdi M, Gülmezoglu AM, et al. Characteristics of Randomized Controlled Trials Included in Systematic Reviews of Nutritional Interventions Reporting Maternal Morbidity, Mortality, Preterm Delivery, Intrauterine Growth Restriction and Small for Gestational Age and Birth Weight Outcomes1,2. J Nutr. 2003;133(5):1632S-1639S. doi:10.1093/jn/133.5.1632S

2. Afrakhteh M ES, Valayi N. Preterm Labor Incidence and Related Factores. Pejouhandeh. 2003:341-3.

3. Maguire CM, Veen S, Sprij AJ, Le Cessie S, Wit JM, Walther FJ. Effects of basic developmental care on neonatal morbidity, neuromotor development, and growth at term age of infants who were born at $<32$ weeks. Pediatrics. 2008;121(2):e239-245. doi:10.1542/peds.2007-1189

4. Beckwith L, Rodning C. Dyadic processes between mothers and preterm infants: Development at ages 2 to 5 years. Infant Ment Health J. 1996;17(4):322-333. doi:10.1002/(SICI)1097-0355(199624)17:4<322::AIDIMHJ4>3.0.CO;2-O

5. Goldberg S, DiVitto B, Bornstein M. Parenting children born preterm. Handbook of Parenting Volume 1: Children and Parenting. Mahway, NJ; Lawrence Erlbaum Associates;1995:209-231.

6. Greenberg MT, Crnic KA. Longitudinal predictors of developmental status and social interaction in premature and full-term infants at age two. Child Dev. 1988;59(3):554570.

7. Campbell SB. Behavior Problems in Preschool Children. In: Ollendick TH, Prinz RJ, eds. Advances in Clinical Child Psychology. Boston, MA: Springer; 1997:1-26.

8. Cowan PA, Cowan CP, Ablow JC, Johnson VK, Measelle JR. The Family Context of Parenting in Children's Adaptation to Elementary School. Mahwah, NJ: L. Erlbaum Associates; 2005.

9. Bowlby J. A secure base: Parent-child attachment and healthy human development. New York, NY: Basic books; 2008.

10. Westrup B. Family-centered developmentally supportive care. Neoreviews. 2014;15(8):e325-e35.

11. Hildebrandt KA, Fitzgerald HE. The infant's physical attractiveness: Its effect on bonding and attachment. Infant Ment Health J. 1983;4(1):1-12. doi:10.1002/10970355(198321)4:1<1::AID-IMHJ2280040102>3.0.CO;2-2

12. Kussano C, Maehara S. Japanese and Brazilian maternal bonding behaviour towards preterm infants: A comparative study. Journal of Neonatal Nursing-London. 1998;4:23-18.

13. Franck LS, Cox S, Allen A, Winter I. Measuring neonatal intensive care unit-related parental stress. J Adv Nurs. 2005;49(6):608-615. doi:10.1111/j.1365-2648.2004.03336.x

14. Galeshi M, Mirghafourvand M, Alizadeh-Sharajabad F, Sanaati F. Predictors of Mother-Child Bonding. Hayat. 2016;22(1):13-26.

15. van Ijzendoorn $\mathrm{MH}$, Schuengel C, Bakermans-Kranenburg MJ. Disorganized attachment in early childhood: metaanalysis of precursors, concomitants, and sequelae. Dev Psychopathol. 1999;11(2):225-249.

16. Pennestri $\mathrm{MH}$, Gaudreau $\mathrm{H}$, Bouvette-Turcot AA, et al. Attachment disorganization among children in Neonatal Intensive Care Unit: Preliminary results. Early Hum Dev. 2015;91(10):601-606. doi:10.1016/j. earlhumdev.2015.07.005

17. Flacking R, Lehtonen L, Thomson G, et al. Closeness and separation in neonatal intensive care. Acta Paediatr. 2012;101(10):1032-1037. doi:10.1111/j.16512227.2012.02787.x

18. Grosik C, Snyder D, Cleary GM, Breckenridge DM, Tidwell B. Identification of internal and external stressors in parents of newborns in intensive care. Perm J. 2013;17(3):36-41. doi:10.7812/tpp/12-105

19. Korja R, Savonlahti E, Haataja L, et al. Attachment representations in mothers of preterm infants. Infant Behav Dev. 2009;32(3):305-311. doi:10.1016/j.infbeh.2009.04.003

20. Borghini A, Pierrehumbert B, Miljkovitch R, Muller-Nix C, Forcada-Guex M, Ansermet F. Mother's attachment representations of their premature infant at 6 and 18 months after birth. Infant Ment Health J. 2006;27(5):494508. doi:10.1002/imhj.20103

21. Als H, Duffy FH, McAnulty G, et al. NIDCAP improves brain function and structure in preterm infants with 
severe intrauterine growth restriction. J Perinatol. 2012;32(10):797-803. doi:10.1038/jp.2011.201

22. Montirosso R, Del Prete A, Bellu R, Tronick E, Borgatti R. Level of NICU quality of developmental care and neurobehavioral performance in very preterm infants. Pediatrics. 2012;129(5):e1129-1137. doi:10.1542/ peds.2011-0813

23. Meyer EC, Coll CT, Lester BM, Boukydis CF, McDonough $\mathrm{SM}$, Oh W. Family-based intervention improves maternal psychological well-being and feeding interaction of preterm infants. Pediatrics. 1994;93(2):241-246.

24. Gardner SL, Hagedorn MI. Physiologic sequelae of prematurity: the nurse practitioner's role. Part VI. Feeding difficulties and growth failure. (Prevention, intervention, parent teaching, and complications). J Pediatr Health Care. 1991;5(6):306-314.

25. Landsem IP, Handegard BH, Tunby J, Ulvund SE, Ronning JA. Early intervention program reduces stress in parents of preterms during childhood, a randomized controlled trial. Trials. 2014;15:387. doi:10.1186/1745-6215-15-387

26. Nicolaou M, Rosewell R, Marlow N, Glazebrook C. Mothers' experiences of interacting with their premature infants. J Reprod Infant Psychol. 2009;27(2):182-194. doi:10.1080/02646830801922796

27. Sehgal A, Stack J. Developmentally supportive care and NIDCAP. Indian J Pediatr. 2006;73(11):1007-1010. doi:10.1007/bf02758309

28. Sizun J, Westrup B. Early developmental care for preterm neonates: a call for more research. Arch Dis Child Fetal Neonatal Ed. 2004;89(5):F384-388. doi:10.1136/ adc. 2002.025114

29. Kleberg A, Westrup B, Stjernqvist K. Developmental outcome, child behaviour and mother-child interaction at 3 years of age following Newborn Individualized Developmental Care and Intervention Program (NIDCAP) intervention. Early Hum Dev. 2000;60(2):123-135.

30. Meijssen D, Wolf MJ, van Bakel H, Koldewijn K, Kok J, van Baar A. Maternal attachment representations after very preterm birth and the effect of early intervention. Infant Behav Dev. 2011;34(1):72-80. doi:10.1016/j. infbeh.2010.09.009

31. Borimnejad L, Mehrnoosh N, Fatemi NS, Haghani H. Impacts of creating opportunities for parent empowerment on maternal stress: A quasi-experimental study. Iran J Nurs Midwifery Res. 2013;18(3):218-221.

32. Karbandi S, Momenizadeh A, Hydarzadeh M, Mazlom $S$, Hasanzadeh M. The effect of mother empowerment program on mothers' attachment to their hospitalized premature neonates. Evidence Based Care. 2015;5(2):7-14. doi:10.22038/ebcj.2015.4498
33. Melnyk BM, Feinstein NF, Alpert-Gillis L, et al. Reducing premature infants' length of stay and improving parents' mental health outcomes with the Creating Opportunities for Parent Empowerment (COPE) neonatal intensive care unit program: a randomized, controlled trial. Pediatrics. 2006;118(5):e1414-1427. doi:10.1542/peds.2005-2580

34. Mirghafourvand M, Ouladsahebmadarek E, Hosseini MB, Heidarabadi S, Asghari-Jafarabadi M, Hasanpour S. The Effect of Creating Opportunities for Parent Empowerment Program on Parent's Mental Health: A Systematic Review. Iran J Pediatr. 2017;27(2):e5704. doi:10.5812/ijp.5704

35. Vamegi R, Habibollahi A, Lornejad H, et al. Standardization of Ages and Stages Questionnaire in Iranian Children. Tehran; 2010.

36. Yang MB, Donovan EF, Wagge JR. Race, Gender, and Clinical Risk Index for Babies (CRIB) Score as Predictors of Severe Retinopathy of Prematurity. J AAPOS. 2006;10(3):253-261. doi:10.1016/j.jaapos.2006.01.004

37. Condon JT, Corkindale CJ. The assessment of parentto-infant attachment: Development of a self-report questionnaire instrument. J Reprod Infant Psychol. 1998;16(1):57-76. doi:10.1080/02646839808404558

38. Feldman R, Eidelman AI, Sirota L, Weller A. Comparison of skin-to-skin (kangaroo) and traditional care: parenting outcomes and preterm infant development. Pediatrics. 2002;110(1 Pt 1):16-26.

39. Sohrabi S, Ahmadi Z, Mosayebi Z, Haghani H. Effect of Infant Massage by Mothers on Maternal Attachment Behavior in Infants Hospitalized in Neonatal Care Units. Hayat. 2014;20(2):59-68.

40. Glasser R. Method of delivery and maternal infant attachment. ProQuest; 2007.

41. Moghaddam Hoseini V, jaafarnejadf@mums.ac.ir. Impact of Maternal Attachment Style on Mother to Infant Attachment. Qom Univ Med Sci J. 2011;5(3):87-91.

42. Dezvaree N, Alaeekarahroudi F, KhanaliAgan L, TalebiGhane E. The Mother-Newborn s Attachment and Its Related Factors in Mothers of Hospitalized Preterm Neonates. Journal Health Care. 2016;17(4):340-349.

43. dadipoor S, Rajaei M, Ahmadi Kani Golzar A, et al. Investigating the degree of mother-infant attachment among the visitors of Bandar Abbas hospitals Bandar Abbas hospitals. Pars of Jahrom University of Medical Sciences. 2014;12(2):17-23.

44. Insel TR. A neurobiological basis of social attachment. Am J Psychiatry. 1997;154(6):726-735. doi:10.1176/ajp.154.6.726

45. Carter CS. Neuroendocrine perspectives on social attachment and love. Psychoneuroendocrinology. 1998;23(8):779-818

Copyright (C) 2018 The Author (s); This is an open-access article distributed under the terms of the Creative Commons Attribution License (http://creativecommons.org/licenses/by/4.0), which permits unrestricted use, distribution, and reproduction in any medium, provided the original work is properly cited. 